\title{
Vassilis Argyroulis*
}

University of Thessaly, Greece

vargi@uth.gr

\section{INVESTIGATING STUDENT MOTIVATION IN THE USE OF CORPUS CONCORDANCING IN ESP LEARNING AT UNIVERSITY LEVEL}

\section{Abstract}

This article is the qualitative part of a broader research project focusing on teaching English for Specific Purposes (ESP) via corpus concordancing in a university. A corpus of ten million words was assembled containing texts from the domains of Special Education, General Academic English, and General English. A corpus teaching method (CTM) was compared and contrasted to a traditional teaching method (TTM) in terms of student motivation. I particularly explored what it is that motivates mixed-ability level university students when involved in corpus concordancing compared and contrasted with existing traditional learning practice. Data collection procedures to estimate motivation were item analysis of a motivational questionnaire, an open-ended survey, and a corpus style analysis of the survey. Important features were demonstrated that motivate or demotivate students of three ability levels (beginner, intermediate, advanced) when following CTM or TTM. A major finding was that a substantial proportion of beginners suggested corpora be used in learning vocabulary, ascribing high motivational value to it. While this proportion is smaller than those with the other two student ability levels, it suggests they do wish to use corpora in learning vocabulary despite being cautious. Finally, some teaching implications are provided to be considered by ESP teachers at university level.

\section{Key words}

English for specific purposes, corpus concordancing, motivation, corpus teaching, data-driven learning.

* Corresponding address: Vassilis Argyroulis, 21 Stratonikias St., Larissa, Greece. 


\section{INTRODUCTION}

This article presents a comparative analysis between two approaches to teaching English for Specific Purposes (ESP) to university students who have Greek as their native language. The traditional approach involves the existing method used in ESP courses, typically consisting of reading handouts of academic English texts in class and developing strategies to understand unknown vocabulary or grammatical phenomena. The new method involves making use of electronic corpora, which are collections of texts in electronic form used for linguistic research and language teaching. This linguistic research is facilitated by electronic search engines called corpus concordancers. For the purposes of this investigation I compiled my own corpus, the Thessaly Corpus, counting ten million words. This research was born out of the necessity to modify and improve the ESP course of the Pedagogical Department of Special Education of the University of Thessaly. The overall research project included (a) a quantitative part in which students performed language tasks and their performance was measured, and (b) a qualitative part in which student motivation was assessed. The present article focuses on the latter.

\section{CORPORA IN THE ESP CLASSROOM}

This study has been influenced by practical applications of corpus linguistics that have offered extremely useful methodological approaches to communicative language teaching in ESP and broader settings. Sinclair $(1990,2003)$ connected corpus linguistics with the communicative teaching approach. His studies on corpora, collocations, idioms, and concordance lines have greatly influenced language teachers and researchers because they have proved that corpora can effectively clarify grammatical phenomena and lexical choices. Furthermore, his studies suggest what should be prioritized in language learning and, more importantly, they develop different and more imaginative ways of learning and teaching. By improving their accessibility and relevance to students, corpora or subcorpora of specific disciplines can sometimes be more suitable than general corpora in teaching languages for specific purposes and they usually benefit students who study ESP at university level (Allan, 2009). For example, Chang (2014) compared the online Corpus of Contemporary American English (COCA) with a manually collected specialized corpus (named Michelangelo) by analyzing data from a longitudinal, ESP writing skills experiment in Korea. Chang's sample included 10 intermediate to advanced English language students who were told to consult both the general and the specialized corpora to perform various academic writing tasks over a period of 22 weeks with teaching sessions once a week. The researcher's primary data was based mainly on transcripts of weekly interviews and students' written responses to survey questions (Chang, 2014: 247-248). 
In his influential paper, Tribble (1997) offered useful and practical ideas and applications of corpus linguistics in language education in academic settings such as the present one. Rather than simply offering a formula for using a specific reference resource for teaching and learning language, Tribble's examples of concordancer use and suggested task types provided an incentive for many corpus teachers around the world (including myself) to seek empirical corpus evidence in support of teachers' and/or researchers' claims and to create appropriate corpus concordancing tasks to assign to students. Barlow (2003) worked extensively and authoritatively on corpus and concordancing software development and hence many teachers, including myself, decided to use his valuable, hands-on, Monoconc Pro 2.2 (or MP2.2) concordancing tool (Barlow, 2003) in corpus research efforts. In a work of great importance in the field of corpus linguistics, Mahlberg (2005) highlighted the serendipitous nature of corpus technology, which allows researchers to realize phenomena they had never imagined, and the vast potential of corpora "to bring to light facts about language that may be hidden from our intuitions" (Mahlberg, 2005: 38). This study is, to some extent, inspired by Mahlberg's work in that it aims to provide empirical corpus data from qualitative viewpoint by testing students' awareness not only of the frequencies of keywords in context (KWIC) occurrences but also their "semantic prosodies," in other words, semantically positive or negative occurrences (Mahlberg, 2005: 23). Further relevant literature has indicated a functional relationship between corpus linguistics (CL) and communicative language teaching (CLT) with progress in computer science certainly being a catalyst in this relationship. As regards the catalytic effect of computers on this relationship, Kennedy (2014) clearly states "it would have been surprising if the introduction of any technology as revolutionary as computing had not had consequences for the study of language" (Kennedy, 2014: 268). In other words, being able to use a PC to quickly analyze features of language in so many texts could be influential for teachers and learners. This is relevant to this study because there has been an effort to find and explore different methods of teaching ESP with the aid of computer programs. Such use of computers may be more interesting and effective than the traditional teaching approach that has been in use for so long. Thus, in this study, corpus concordancing was examined as a potentially helpful way of improving my ESP course.

In an effort to create a more motivational ESP course, Önder-Özdemir (2014) investigated the relevance of corpus data in medical English instruction via datadriven learning (DDL). In her longitudinal study, Önder-Özdemir (2014) employed an experimental group of 323 first-year Turkish medical students with a focus on teaching collocations found in medical English articles taken from a relevant medical journal. After investigating medical collocations of genre-specific target words, the students were asked to underline and talk about them with the instructor. At a later stage, they were asked to complete a self-initiated project to discover their own medical collocations and provide written reports. After the longitudinal experiment, the students were more confident in exploring medical collocations via DDL because 
they had found uses that were not present in dictionaries (Önder-Özdemir, 2014: 41).

Thus, corpus concordancing has established its position in CLT and ESP, signaling an "extendability" (Gries, 2013: 159) or simply a shift from a focus on single words to multi-word items and, perhaps most importantly, facilitating learning processes "by providing a rich source of embodiments and contexts from new vocabulary" (Cobb as cited in O'Keefe, McCarthy, \& Carter, 2007: 24) and dissolving language ambiguity (Geluso \& Yamaguchi, 2014: 226). Furthermore, learning via corpus concordancing, or more broadly DDL, in ESP settings has provided a unique opportunity for practitioners and researchers to explore learners' preferences and attitudes toward this type of teaching and learning methodology in comparison with other more traditional ones. For instance, Mizumoto, Chujo, and Yokota (2016) focused on student perceptions by constructing and validating a questionnaire designed to measure DDL (or Corpus Teaching Method or CTM here) effects, as is the case in the present study. Similar comparisons were performed by Marinov (2018), Forti (2019), and Elmansi et al., (2021), who created special instruments for measuring students' attitudes and preferences as regards DDL.

\section{METHODOLOGY AND RESEARCH DESIGN}

As stated above, the qualitative component of the study addresses what aspects of the two methods, Traditional Teaching Method (TTM) and Corpus Teaching Method (CTM), motivate or demotivate university students, and why. The first step in addressing these questions was to design an open-ended survey containing five questions (see Section 4) and assign it to all the students (both TTM and CTM groups), no matter what their language ability level was. The students provided written responses which were analyzed thematically and categorized in an explicit manner according to their similarity or dissimilarity. This was also the case for multiple responses given by a single student to one question, which is in line with Tong, Sainsbury, and Craig (2007: 356) who maintain that "the credibility of the findings can be assessed if the process of coding, and the derivation and identification of themes are made explicit."

The next step was to make a comparison between the categories of responses in order to draw conclusions about features that most frequently motivate or demotivate students when being taught via CTM or TTM.

Because this research took place in the university classroom where I teach, I used Action Research as the overall research paradigm for this study (Craig, 2009; Creswell, 2009; Gay, Mills, \& Airasian, 2009; Plano Clark \& Creswell, 2010). According to Gay et al. (2009: 18), Action Research in education involves systematic research performed in the teacher's environment to collect data about how students learn and how teachers teach. 
The qualitative component (open-ended survey) was used to support findings from the quantitative component, with the latter being beyond the scope of this article. Performance results from the tasks were combined with student responses to open-ended questions concerning the two teaching methods in order to explore how and why students reacted in different ways to TTM and CTM. The qualitative component of the study is aimed to provide an in-depth understanding of (a) the students' experiences with TTM and CTM, (b) their perceptions of the two different methods, and (c) their perceptions regarding the extent to which these two methods motivated them or not to make progress in class.

The experimental method is also suitable when participants are randomly selected into their respective groups or matched on key characteristics (Cook \& Campbell, 1979; De Vaus, 2001; Meltzoff, 2010). The two groups of participants being compared are assumed to be equivalent due to random selection, a method whereby a population of interest is identified, and each member of the population has an equal chance of being chosen as part of the sample. Two groups of participants were selected for this study (G1 and G2 respectively, 30 students each). The two groups were stratified based on ability level, which is the moderator variable (19 beginner students, 22 intermediate students, and 19 advanced students). The students were then selected from the stratified groups. Due to the nature of the sampling, the two groups were analogous.

The study consisted of two phases. In the first session, both groups were given the same text or specialized passage (SP1), but the teaching approach was different: G1 was assigned four tasks that involved reading SP1 and working on target vocabulary via CTM, whereas G2 did exactly the same via TTM. In the second session, both groups were given the same specialized passage (SP2), which was different from the one used in the previous session. This time G2 was assigned four tasks that involved reading SP2 and were working on target vocabulary via CTM, and G1 did the same via TTM.

The experimental setup differs slightly from the traditional two-group experiment in that the control group became the experimental group and the initial experimental group became the control one. In other words, a within-subjects design was used because both groups of 30 students received both CTM and TTM, therefore providing some counterbalance. The reasoning behind employing a within-subjects design is that subjects function as their own control (Keren \& Lewis, 2014: 260). This provides the opportunity for a researcher to instantly compare the different treatments. Statistically speaking, it increased the sample size of participants when using both teaching methods and, from a qualitative point of view, students were encouraged to express their feelings and attitudes to a greater extent. The within-subjects design ensured that both groups of participants were exposed to both methodologies and therefore a parity of student experiences was achieved.

After the two teaching sessions were completed, student performance was measured in terms of the percentage of correct answers in the tasks completed (see 
sample worksheet in Appendix 1), and motivation was measured using a student motivation questionnaire (see the item pool in Appendix 2).

\section{QUALITATIVE ANALYSIS OF SURVEY DATA}

This section presents the findings from the qualitative analysis of the study after considering the methodology described above. The objectives of the qualitative part of this study were to determine to what extent student motivation informs preferred teaching style when asked to compare CTM and TTM, and to identify motivational and demotivational factors when using one method or the other. To fulfill these objectives, after completing the language task stage and the quantitative questionnaire stage (four exercises and one Likert scale questionnaire, respectively), sixty students who participated in this study were asked to respond to an Open-Ended Survey (OES) which asked the following five questions about CTM and TTM:

1. What did you like best about CTM and TTM?

2. What did you like least about CTM and TTM?

3. What were the most challenging aspects of CTM and TTM?

4. Which method do you believe motivated you more to learn and why?

5. Which one of the two methods would you suggest to a friend and why?

According to Dörnyei (2007: 107), open-ended questions (a) allow wider freedom of expression, and (b) are used when the scope of answers is not known. In this research, the short answer question type was selected because it can be answered succinctly with a response, which is usually more than a phrase and less than a paragraph.

The students' responses were analyzed via thematic analysis. In the current section, the categorization process and the subcategories will first be described. I will then analyze responses within each subcategory with their frequencies in order to identify students' specific reasons when responding to questions about CTM and TTM. Thereafter, responses across ability levels will be presented. Then, reflections on important aspects of the responses to the OES will follow. Finally, a corpus-style approach to the responses to the OES will be provided.

\subsection{The categorization process}

Both the top-down and bottom-up approaches were used to categorize the qualitative responses, as described previously. A holistic top-down approach allowed for observation of trends in the qualitative responses that were then compared and contrasted with the trends in the quantitative results, thus allowing 
triangulation of the results. At the same time, a bottom-up atomistic approach provided a detailed picture of the responses. Dörnyei (2007: 26) comments on the "ideological contrast" between the quantitative and qualitative categorization and/or coding practices. While quantitative research can launch a research study with exact coding tables for processing the data, qualitative categorization is different because (a) it is not numeral but verbal, adding up to small textual labels such as the ones provided by my students when they responded to the OES, and (b) it is often not defined on the basis of a theory or hypothesis but is left as open as possible in order to include the little niceties of meaning embedded within my students' written data, which were usually hidden throughout the investigation. In line with theoretical grounding on coding (Busse \& Walter, 2013; Creswell, 2009; Dörnyei, 2007; Tong et al., 2007), sixty tables were created, one for each student. Then, based on the questions, the following five categories were created:

1. Reasons for liking CTM and TTM

2. Reasons for not liking CTM and TTM

3. Challenging aspects of CTM and TTM

4. Reasons why CTM and TTM motivated me to learn

5. Reasons for suggesting CTM and TTM to a friend.

According to the responses that were spread over each one of the five categories, fifty-nine subcategories of responses were created. This was done by identifying and merging subcategories of responses that were linguistically and semantically synonymous. For example, some students had the following responses to the second question about CTM (what did you like the least?):

1. It was difficult for me to understand the meaning of unknown words.

2. It was difficult for me to read the text.

3. The content of the text was nonsensical and superficial to me.

4. The text was confusing to me.

Since the above responses had similar meanings, they were put into a single subcategory, "content nonsensical." While categorizing, I assumed that no response could be exactly the same unless by chance so, for instance, responses that explicitly or implicitly reflected difficulty in comprehension were placed in the same category. The list of fifty-nine subcategories is presented in Table 1. 


\begin{tabular}{|c|c|c|}
\hline Category & стM Subcategories & TTM Subcategories \\
\hline Like best & $\begin{array}{l}\text { Convenient } \\
\text { Effective for understanding } \\
\text { Interesting } \\
\text { Use of technology } \\
\text { Variety of examples, options }\end{array}$ & $\begin{array}{l}\text { Access to content } \\
\text { Consistent } \\
\text { Easy } \\
\text { Effective for understanding } \\
\text { Interesting } \\
\text { Teacher feedback } \\
\text { Variety of learning strategies }\end{array}$ \\
\hline Like least & $\begin{array}{l}\text { Tiring (boring) } \\
\text { Computer delays/unfamiliarity } \\
\text { Content nonsensical } \\
\text { Inconsistent } \\
\text { Specific tasks } \\
\text { Too many sentence examples } \\
\text { Nothing I disliked }\end{array}$ & $\begin{array}{l}\text { Boring } \\
\text { Different process than CTM } \\
\text { Ineffective for understanding word meanings } \\
\text { Requires more time } \\
\text { Specific tasks } \\
\text { Too few example sentences } \\
\text { Lack of help or guidance }\end{array}$ \\
\hline $\begin{array}{l}\text { Most challenging } \\
\text { aspects }\end{array}$ & $\begin{array}{l}\text { No challenging aspects } \\
\text { Computer searches/problems } \\
\text { Multiple sample sentences } \\
\text { New method of learning } \\
\text { Specific tasks } \\
\text { Time to complete task }\end{array}$ & $\begin{array}{l}\text { No challenging aspects } \\
\text { Difficult } \\
\text { Exercises } \\
\text { Specific tasks } \\
\text { Positive aspects } \\
\text { Text and context-based learning } \\
\text { Time to complete task } \\
\text { Tiring and uninteresting } \\
\text { Too few sample sentences }\end{array}$ \\
\hline $\begin{array}{l}\text { Reasons for } \\
\text { motivation }\end{array}$ & $\begin{array}{l}\text { Easy and enjoyable } \\
\text { Comprehension } \\
\text { Creative } \\
\text { Faster } \\
\text { Variety of sample sentences }\end{array}$ & $\begin{array}{l}\text { Comprehension } \\
\text { Fewer sample sentences } \\
\text { interesting } \\
\text { Text-based content easier to read } \\
\text { Traditional and familiar }\end{array}$ \\
\hline $\begin{array}{l}\text { Why suggest to a } \\
\text { friend }\end{array}$ & $\begin{array}{l}\text { Convenient } \\
\text { Effective } \\
\text { Enjoyable } \\
\text { Interesting } \\
\text { Modern } \\
\text { Personal experience } \\
\text { Variety of sample sentences } \\
\text { Can verify results }\end{array}$ & (No reasons given) \\
\hline
\end{tabular}

Table 1. List of merged CTM and TTM subcategories of synonymous student responses

\subsection{Summary of findings}

A summary of the findings follows, in which comparisons and contrasts between the main subcategories of reasons for the two methods are presented. This will be done in order to see the students' trends in the reasons they gave as regards the OES questions. As will be described, the key findings were (a) all the students liked CTM but not all of them liked TTM, (b) the primary reason for not liking both CTM and TTM was boredom, (c) the most challenging aspects of CTM identified by students were dealing with multiple sample sentences and word meanings, and problems with computer searches, (d) a wide majority of the student sample believed that CTM motivated them to learn more, and (e) a vast number of the students indicated that they would recommend CTM to a friend.

\subsubsection{Reasons for liking CTM and TTM}

All the students liked CTM but they did not all like TTM. The primary reason for liking CTM (as identified by 32\% of responses) was the variety of sample sentences, and the primary reason for liking TTM (as identified by $21 \%$ of responses) was the variety of learning strategies. Students categorized in the intermediate (36\%) and 
beginner (33\%) levels gave this reason more often than the advanced students (28\%). This finding is important because teachers usually assume that beginners may become confused when faced with a variety of examples; however, these results show that, although worthy of some attention, it is not a major problem and was welcomed by the students.

\subsubsection{Reasons for not liking CTM and TTM}

The main reason for not liking CTM and TTM was boredom. This was almost the same response across all ability levels (38\% of advanced, $50 \%$ of intermediate, and $52 \%$ of beginner students about CTM while $51 \%$ of advanced, $53 \%$ of intermediate, and $46 \%$ of beginner students about TTM). Students also indicated that they thought that CTM had too many sample sentences (22\%) and students did not like the fact that TTM had very few sample sentences $(17 \%)$.

\subsubsection{Most challenging aspects of CTM and TTM}

The most challenging aspects of CTM identified by students were dealing with multiple sample sentences and word meanings (51\%) and problems with computer searches (28\%). It is worth noting that the challenging aspects of CTM appeared to vary across ability levels. The majority of students who were categorized as advanced level (63\%) and intermediate level (57\%) reported that their primary challenge with CTM was that it had multiple sentences and word meanings. However, the majority of students who were categorized as beginner level indicated that their primary challenge had to do with computer searches and technical issues (42\%).

The most challenging aspects of TTM were that it involved text and contextbased learning (identified by $23 \%$ of responses) and it was difficult (19\% of responses). As with the challenges of CTM, the demanding aspects of TTM appeared to differ across ability levels. Advanced students were challenged by the text and context-based learning process of TTM, an issue identified by $26 \%$ of advanced students. Intermediate students were also challenged by this context-based process (26\% of responses), and by the TTM exercises (26\% of responses). Students categorized as being at beginner level were challenged by TTM because it provided very few sample sentences (26\% of responses).

\subsubsection{Reasons why CTM and TTM motivated students to learn}

Ninety-five percent of the student sample believed that CTM motivated them to learn more; students provided one hundred and one responses to this item. As noted earlier, regardless of ability level, students indicated that the primary reason CTM motivated them to learn more was because it was creative and interesting. Students classified as intermediate and beginner levels reported that another reason CTM 
motivated them to learn more was because it provided a variety of sample sentences.

Only $33 \%$ of participants indicated that TTM motivated them to learn more; only ten responses for TTM were offered in total. Students at the intermediate level indicated that the reasons TTM motivated them to learn more were because its textbased content was easier to read (33\% of responses) and it was traditional and familiar to them (33\% of responses). Students classified as beginners noted that TTM motivated them to learn because it provided them with fewer sample sentences (67\% of beginner participants).

\subsubsection{Reasons why students recommend CTM and TTM to others}

Most of the students (95\%) indicated that they would recommend CTM to a friend. In contrast, only a minority (22\%) reported that they would recommend TTM to a friend; these students did not, however, provide reasons for their decision. Reasons for recommending CTM to a friend appeared to differ across ability levels, for example, advanced ability students chose to recommend CTM to a friend because it was effective (23\%) and interesting (20\%). Students at the intermediate ability level indicated that they would recommend CTM because it was modern $(29 \%)$ and convenient (24\%). Students in the beginner group stated that they would recommend CTM to a friend because it was convenient (37\%) and effective (30\%).

\subsection{Corpus-style approach to the responses to the OES}

A corpus approach to the responses to the OES (qualitative data) offers a deeper insight into the reasons why the students were motivated or demotivated by CTM and TTM. The analysis of student responses and the corpus approach offered in this study, together with the triangulation with the previous quantitative findings, can contribute to making research-informed teaching decisions. To perform the corpus analysis, the open-ended responses that the beginner, intermediate, and advanced level students gave about CTM and TTM were collected and put in separate text files to be inserted into the MP2.2 concordancing program.

\subsubsection{Process of conducting corpus analysis}

To gain a deeper insight into why the majority of beginner level students (BLSs) were not motivated by or did not like CTM, a text file (LOW SS on CTM, where "LOW" stands for "beginner") containing all their opinions about CTM (as shown in Figure 1) was inserted. 


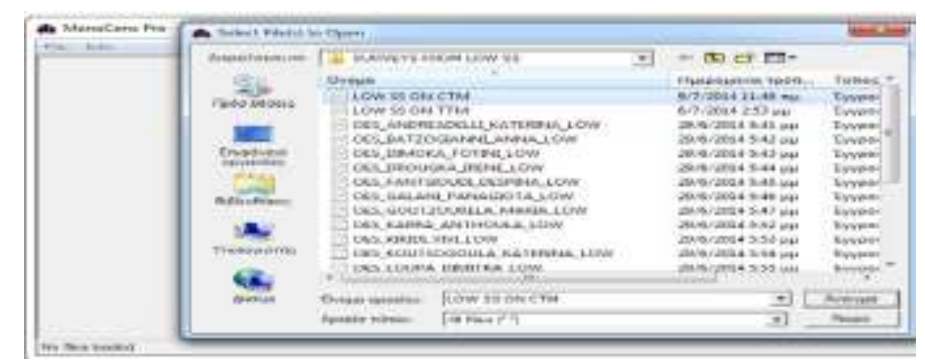

Figure 1. Insertion of LOW SS on CTM text file in the MP2.2 program

The negation word "not," the adjective "more," and the noun "meaning" were selected as KWICs to be entered in the program. The word "not" was chosen to obtain a deeper and more qualitative picture of what bothers students about the two methods. It is useful to see what comes before and after the negation word "not" in their written responses in order to understand their feelings about the two teaching methods. Similarly, the word "more" was chosen to see what they actually say when comparing CTM with TTM. Finally, the noun "meaning" was selected because understanding the meaning of target words is within the aims of CTM and TTM and it is important to see how the students relate the two methods to their ability to understand the meaning of unknown words; looking at what comes before and after the KWIC meaning might offer a deeper understanding of students' attitudes and feelings toward CTM and TTM. As mentioned previously, the literature supports the idea of scrutinizing individual examples in context (Mair, 1996) and performing more in-depth analyses and interpretations of authentic language (Hasko, 2013).

\subsubsection{Collocates of not}

To examine why most of the BLSs had a negative opinion of CTM, the KWIC not was typed in the concordancing program so as to elicit their negative sentences. As shown in Figure 2 below, 14 concordance lines were obtained.

Frequent collocates appear in red in MP2.2 to help observe the words that were more consistently used before and after not by the students. I will present the figures as images rather than text-only concordance lines so that red collocates are easily discerned.

more interesting This one because I was not bored It was very interesting the ctm It w to find out the meaning of the words. I did not like that method because required knowli elpful to remember the words that you do not know. It is a fast program that finds imme nderstand the meaning of the world. I did not like very much the fact that this method $v$ d to create sentences with them. There is not consistency therefore I can not understai - There is not consistency therefore I can not understand the meaning of words. There iderstand the meaning of words. There is not a challenging aspect of the method CTM dual and complete sentences and $I$ could not find the meaning. There is not a consiste and $I$ could not find the meaning. There is not a consistency. There is not a challengin ing. There is not a consistency. There is not a challenging aspect of CTM for me. The it. The CTM was faster. The student does not get tired and are equally valid. The CTM am execution and more for those that did not know. I believe that CTM gave me the me Because is more modern, fast, and does not tire and the child learns many more in qu ormation, enriches the vocabulary and is not at all tiring for him. ...

Figure 2. Fourteen of 14 concordance lines of not from BLSs' responses regarding CTM 
Figure 2 offers an insight into how the BLSs see CTM. They used the word "not" in 14 sentences; however, in 8 of 14 concordance lines $(1,3,7,10,11,12,13,14)$ the word "not" was used in a positive way, such as "not tire," "not bored," "not at all tiring," etc. In the six clearly negative opinions, the BLSs raised issues of the consistency of concordance lines and time which will help teaching decisions in future attempts to incorporate the Thessaly Corpus in teaching practice. For instance, to alleviate the abovementioned problem of inconsistency, more targeted corpora in terms of content for each particular level of student might be suggested. In the same way, a search was carried out in the BLSs' responses about TTM using the same concordancing program and the same KWIC (not). The aim was to examine the BLSs' negative opinions about the use of TTM in order to compare them to the students' opinions about CTM. The following concordance lines in Figure 3 show the BLSs' responses when asked to reflect on TTM:

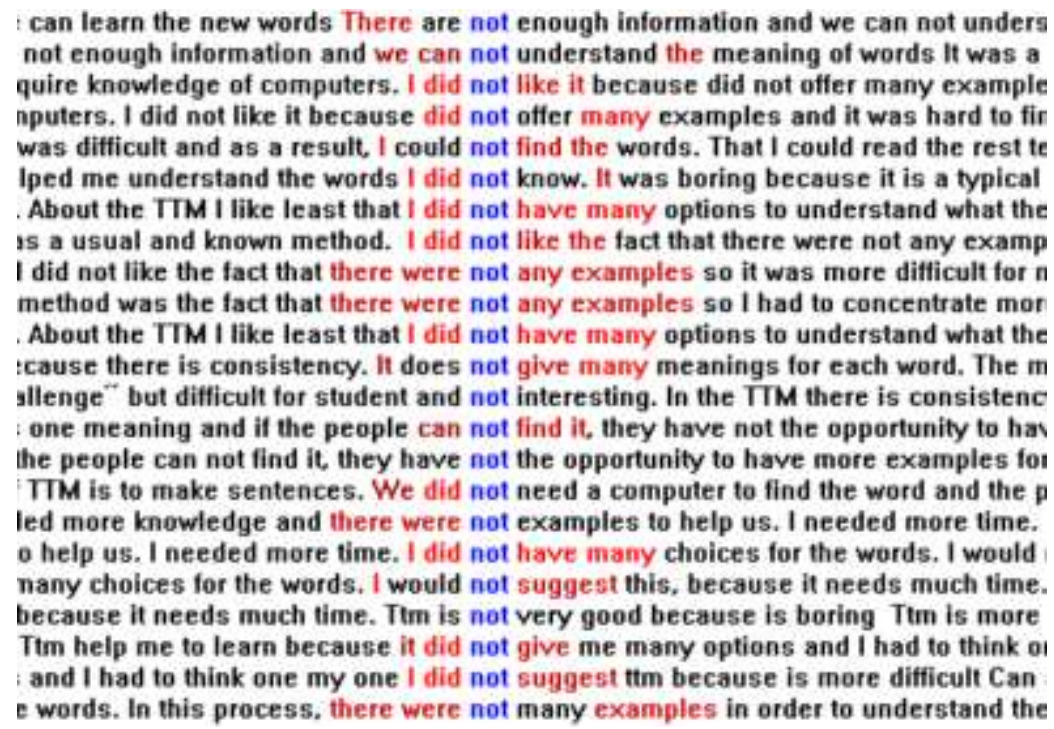

Figure 3. Twenty-three of 23 concordance lines of not from BLSs' responses regarding TTM

Commenting on the TTM, the BLSs used the word "not" in 23 sentences of their written responses to the OES; the collocates of the word "not" show that in 23 of 23 sentences, the word "not" was used in a negative way, such as "not like," "not many examples," "not suggest," etc. The BLSs raised issues of the insufficiency of examples, loss of interest, boredom, and so on.

A similar comparison was performed between the responses of the intermediate level students (ILSs) about CTM and TTM. The following concordance lines in Figure 4 show the ILSs' responses to CTM: 


\begin{abstract}
understand the given word. There were not anything particular that I did not like. If s : re were not anything particular that I did not like. It s a new method and I had the appo a faster and more effective method. It is not so specific search and the results may be showing the results I think that CTM did not motivate me because I had to use the con is and this was good because if I would not understand 1 or 2 sentence. 1 go to next $e$ to next example, there is no possibility not to understand the meaning of the wanted, as something new and interesting. I did not have to do in the past with similar methoc e wanted word. I mostly like when I did not understand the meaning of the word and $t$ ien I will remember it the next day. I did not really enjoy that there are many texts and word which I am looking for. There was not any challenging aspect of CTM method. I the words. I like very much CTM.I have not got something that I like me least. The me Ising of computer in the classroom. I do not like the size of the letters. It was ditficult I tarnt something from this method. I did not teally like the passages due to the fact th: itained 7 to 10 words. This method I do not believe that motivated me to learn, consic h time as a result to get boring. I would not suggest to a friend this method because i which made it easy to understand. I did not like creating sentences in task 3 . We had he method TTM. In the CTM method did not like to me that there are lot of examples $w$ results for one word was what I did not like because sometimes it confused me. tcause we used computers. so we were not bored. I can not find something I did not omputers, so we were not bored. I can not find something I did not like. It was not be ot bored. I can not find something I did not like. It was not boring because we used $c$ not find something I did not like. It was not boring because we used computers and a an learn easier with this method and do not forget the words in the future. The chance tunities to understand word that you de not know and finally this method has many ex
\end{abstract}

Figure 4. Twenty-four of 24 concordance lines of not from ILSs' responses regarding CTM

As seen in Figure 4, the ILSs used the word "not" in 24 sentences. However, the collocates of not show that in 13 of 24 concordance lines $(1,2,5,6,7,8,11,19,20,21,22$, $23,24)$ the word "not" was used in a positive way, such as "not bored," "not boring," "no possibility not to understand," "cannot find something I did not like," etc. In the 10 clearly negative opinions, the ILSs raised issues such as confusion due to the great number of concordance lines and ignorance of the new software. The same search about the ILSs' opinions of TTM yielded the following concordance lines, as shown in Figure 5:

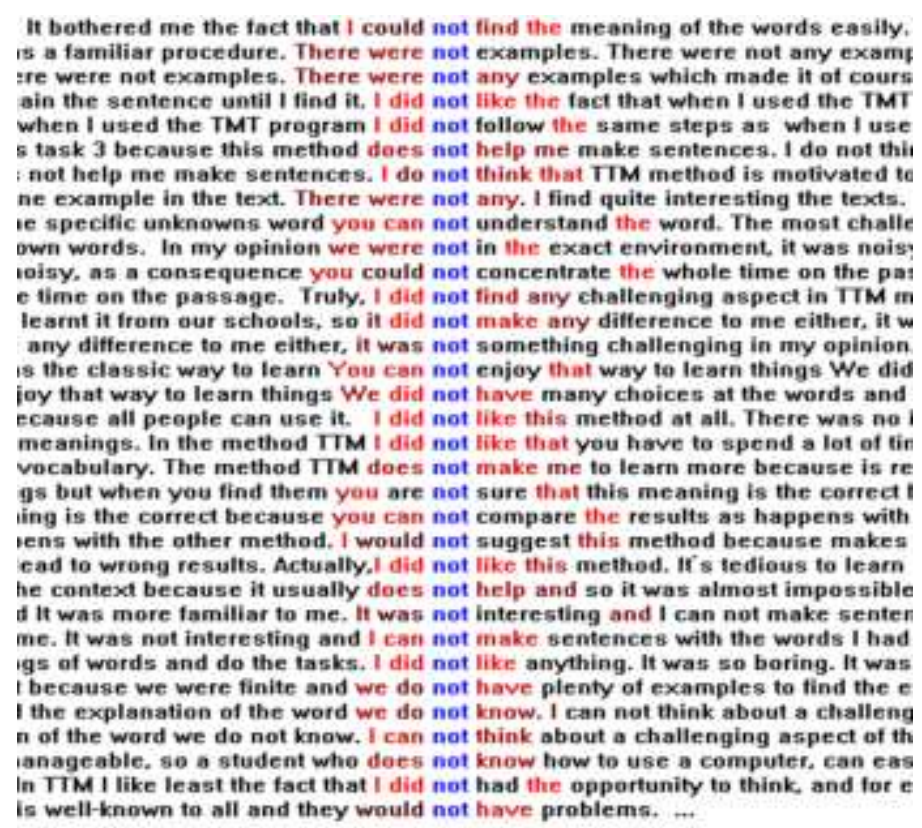

Figure 5. Thirty-three of 33 concordance lines of not from ILSs' responses regarding TTM 
When discussing TTM, the ILSs used the word "not" in 33 concordance lines; in 33 out of 33 sentences, the word "not" was used in a negative way, such as "not like," "not sure," "not suggest," etc. The ILSs raised issues of dislike, loss of interest, boredom, and so on.

A similar comparison was performed between the responses of the advanced level students (ALSs) regarding CTM and TTM. The concordance lines in Figure 6 show the ALSs' responses to CTM:

their meaning. The only thing that was not as good was the exercise that needed to I
elt unable to write them, because I had not found their right meaning. It was more mo
own sentences with words that we did not know exactly that they mean. Task 3 beca
nt kind of meanings the word had. I did not like so much that the meaning of the word
it each word means. The fact that it did not have the whole sentences and after a spo
ffter a spot they were cut off. That it did not help me to understand the meaning of the
the meaning of the word because I did not have whole vision of each sentence. The I
ntences to understand the correct. I did not like Task 3, because I found very difficult
rstand easier the unknown words. I did not like the task 3 where we had to write our a
re had to write our own sentences. I do not think that it had any challenging aspects.
: it easier to understand the word. I did not like very much the fact that it takes some
i the end that seems enjoyable (so if s not really a problem, you just have to get use
tiring Task 3 because many words are not totally understood so it was difficult to cor
to make sentences with words that are not still known for us, so it demanded attentio
delayed the process, but the CTM had not had any considerable disadvantages. The

Figure 6. Fifteen of 15 concordance lines of not from ALSs' responses regarding CTM

The ALSs used the word "not" in 15 sentences; three of 15 concordance lines $(10,12$, and 15) are totally positive. The rest of them are negative but raise very specific issues (e.g., specific task, not whole sentence, etc.). The clearly negative sentences raise issues such as:

- Change of meaning from one concordance line to another

- The exact meaning not found

- Not having the whole vision of a sentence (obviously due to the students not yet being used to the capabilities of the software).

The same search about the ALSs' opinions on TTM yielded the following concordance lines, as shown in Figure 7: 
how to work with that method. I did not like that we had only one example. istudents angry because they can not find the meanings. It was less tirin, $m$. Unfortunately. I sometimes had not even understood the meaning of th to acquire new knowledge. I would not suggest this method to others, bec. is I like most in that method. I can not work with the same happiness with al, so nothing was interesting. I do not like something. There was not a ch I do not like something. There was not a challenging aspect of TTM. It was $\checkmark$ unknown word and even we have not understood a word we can focus on ited options for each word. I would not suggest TTM. because it required $t$ ime, It was a difficult method, I did not like something best. You had only ind out what does it mean. You did not have alternative solutions. Someth I which would help me more. It did not have challenging aspects. As a me and complicated because you did not have a variety of sentences to reac It has many disadvantages. It did not help me. It was difficult for me for $t$ TM I found nothing of interest. I did not like something. You can understan istand entire text. This method I do not think that motivated ssomeone more E meaning in the sentence. I would not suggest a friend this method. It was uggest a friend this method. in was $g$ because it has many tasks it did not give many chances to find the mea the meaning of the unknown words not only from reading the passage but and see what I had written, 1 could not do it. This method was tiring and th : the meaning of the word and I did not have to struggle and find out the $m$ ave in ordinary schools and it was not challenging. This method had not h i not challenging. This methed had not had anything interesting. because cause we are used to it and I would not recommend it to a friend. It did not ause we are used to it and t would not recommend it to a friend. It did not
not recommend it to a friend. If did not take much time to be accomplished weh time to be accomplished. I did not like at all the fact that I had to deal ich more easy. The fact that we did not have examples made it of course $n$ at the same time challenging. I did not really like something: on the contra I of the word only from the text I do not know. It broadens our critical thinki axhausting and boring so we could not pay as attention as it needed. That lat helps to focus on words. It was not so interesting and I had some diftic $e$ meaning of words, because I did not have some assistance [such as co laking my own sentences. TTM did not motivate me more because this me rate me more because this method not only was less interesting but it req ired much more time, too. I would not suggest the traditional methos bec. thod because most students would not be $\$ 0$ interested and attracted to th

Figure 7. Thirty-seven of 37 concordance lines of not from ALSs' responses regarding TTM

The ALSs used the word "not" in 37 sentences; the collocates of not show that in all cases, the word "not" was used in a negative way, such as "not motivated," "not like," "not suggest," etc. The ALSs raised issues of dislike, unwillingness to recommend TTM, uninteresting approach, and so on. A semantically positive occurrence of the word "not" was observed in almost half the responses to CTM (25 of 53), whereas a semantically negative occurrence of the word "not" was observed in all the responses to TTM (93 of 93). The semantic prosody of the word "not" is used to express both contentment and frustration in the case of CTM but only frustration in the case of TTM. Such an observation is congruent with the years of work in corpus and functional linguistic research that clearly points to the role of context and phraseology, not just words, in language and meaning. This supports my argument that the students used the word "not" in a clearly negative sense when commenting on TTM but not when commenting on CTM which reveals that they were definite about their negative opinion of TTM and not that definite about their negative opinion of CTM.

\subsubsection{Collocates of more}

The second stage of the corpus linguistic analysis focused on the most frequent adjective used by students in their responses. The most frequent adjective used by all students when writing about CTM is shown in Figure 8: 


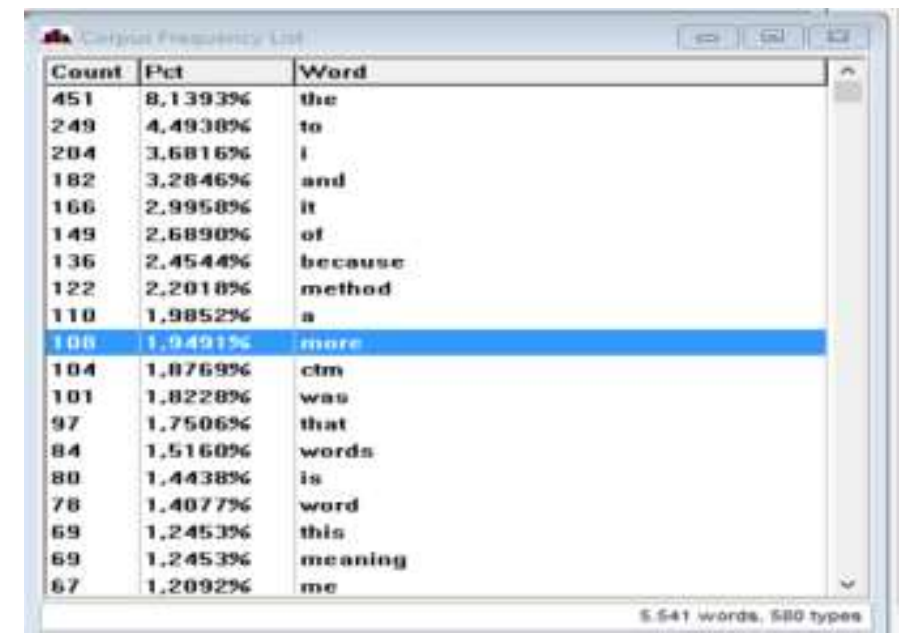

Figure 8. Results for most frequent adjective from student responses regarding CTM

As Figure 8 shows, the most frequent adjective was the comparative "more" (108 times). Figure 9 summarizes the collocates found to the immediate left and the immediate right of more, thus indicating the adjectives or nouns that the students preferred to use before and after more.

\begin{tabular}{|c|c|c|c|c|c|}
\hline & Thett & & 1 fligh & & 2-Alight \\
\hline & & 22 & interesting & 19 & and \\
\hline & was & & to & & lears \\
\hline 16 & & 6 & because & 16 & \\
\hline & and & 6 & & & \\
\hline & learn & 4 & convenient & & the \\
\hline & & 4 & & & \\
\hline & have & 3 & oppertunilites & & for \\
\hline & & & aptions & & because \\
\hline & & 3 & modeen & & \\
\hline & & $\begin{array}{l}3 \\
3\end{array}$ & $\begin{array}{l}\text { ettlective } \\
\text { exangoses }\end{array}$ & & $\begin{array}{l}\text { it } \\
\text { method }\end{array}$ \\
\hline & & 3 & ceasive & & \\
\hline
\end{tabular}

Figure 9. Collocates of more from student responses regarding CTM

As Figure 9 shows, the most frequent word found in the immediate right position was "interesting." The next most frequent was the full infinitive "to learn." To provide more detailed evidence for my claim that most students felt more positively about CTM when compared with TTM, I looked closer at how my students were using the comparative adjective "more" in the corpus of their responses regarding CTM. The concordance lines in Figure 10 show the student responses to CTM: 


\begin{abstract}
... The CTM method is more interesting because we have contact with the chnology. I suggest this method because it is more interesting and you have more opportunities $d$ because it is more interesting and you have more opportunities to learn. It was an easy way to le boring. So many examples may drive us to more answers and to get tired until we finish. I thit fifficult to fill in the blocks, because there was more than one possible meaning for every word. I use I had not found their right meaning. It was more modern and appealed to me, though to the fs in search in computer. The CTM motivates me more to learn than TTM because CTM is a very cri re knowledge. I suggest the CTM because it is more interesting and we have more opportunities $M$ because it is more interesting and we have more opportunities to learn. It was easier, more in ave more opportunities to learn. It was easier, more interesting and included sentences which wh nany words as you want CTM because it was more creative and innovative I liked that we had $n$ rod challenging The CTM method attracted me more than the TTM method because it was somett $\Gamma \mathrm{M}$ method is better than the TTM because the more examples you read about a word the better $t$ id the meaning of the words. Many words had more than one meaning and we had to find the ap! $t$ meaning of the words. CTM, because I learnt more things while using it. Also using computers I while using it. Also using computers makes it more appealing to the students and they pay more $t$ more appealing to the students and they pay more attention to it. I like it because you had a big nethod; it helps me to learn new words. It was more interesting and put me to the curiosity to try ind that helps me very much. CTM definitelyl More attractive, challenging and interesting. Easy ices. Cooperation with the computer. I learned more words than those which had given to me. Th. it those which had given to me. This method is more interesting and attractive for the student. II I believe that first method, CTM, motivated me more to learn because is more creative and easy CTM. motivated me more to learn because is more creative and easy to use for a student like m will find it easy to understand a word reading more than one sentences with the same word. It gi in one sentences with the same word. It gives more chances to find the meaning of the word It w liked use the computer This one because it is more interesting method for learning words it had iging aspects. The CTM method motivated me more to learn because it was more interesting tha od motivated me more to learn because it was more interesting than the other. I would suggest th e words by searching them. This method was more convenient, I could find a word easier and fa to find the suitable meaning. This method was more effective because I could choose the senten ssue. I would suggest this one because it was more convenient than the traditional method. In ar had to find on my own the meaning and it was more helpful for me to remember the meaning of $t$ i. I believe that the CTM motivated me to Iearn more, because I had to struggle in order to find the nd the meaning of the word was maybe a little more time consuming as I mentioned before but I $\mathrm{L}$ I believe that the CTM method motivated me more, because through the examples I would try $\mathrm{t}$ ntences to understand the meaning and it was more easier for me to remember the meaning of th rord Ctm because I think it's better than ttm an more interested It was an innovative way to learn and critical skills This method because it was more interesting and motivate us more to learn ne cause it was more interesting and motivate us more to learn new words CTM because it was mor more to learn new words CTM because it was more creative, enjoying and easier way to learn If
\end{abstract}

Figure 10. Forty of 40 concordance lines of more from student responses regarding CTM

Figure 10 shows how the students used the term "more" at sentence level to explain why they considered CTM "more interesting," "more convenient," "more appealing," and so on. For instance, if we look at the first concordance line from the top of Figure 10 and the first one from the bottom, we can see how the students explained why they felt CTM had something more to offer. To investigate how they used the term "more" to explain their adverse attitude to CTM, we can, for instance, look at the fourth concordance line from the top of Figure 10, "...So many examples may drive us to more answers and to get tired until we finish." The corpus-style analysis thus offers a more in-depth picture of what the students were thinking when they used the comparative adjective "more".

The same searches as shown in Figures 9 and 10 respectively were carried out using the corpus of opinions offered by the students when writing about TTM. Figure 11 summarizes the collocates appearing to the immediate right of more: 


\begin{tabular}{l|l|r|l|}
\hline \multicolumn{2}{l}{ morel] } \\
\hline slay Window Info & & \\
\hline & & 1-Left & 1-Right \\
\hline 6 & is & 10 & difficult \\
3 me & 7 time \\
3 was & 3 to \\
3 much & 3 because
\end{tabular}

Figure 11. Collocates of more from student responses regarding TTM

As Figure 11 shows, the word most frequently used after "more" when students wrote about TTM was "difficult." To provide more detailed evidence for my claim that most students felt there was usually something more negative about TTM when compared to CTM, I looked more closely at how my students were using the comparative adjective "more" in the corpus of their responses regarding TTM. The concordance lines in Figure 12 show the student responses to TTM:

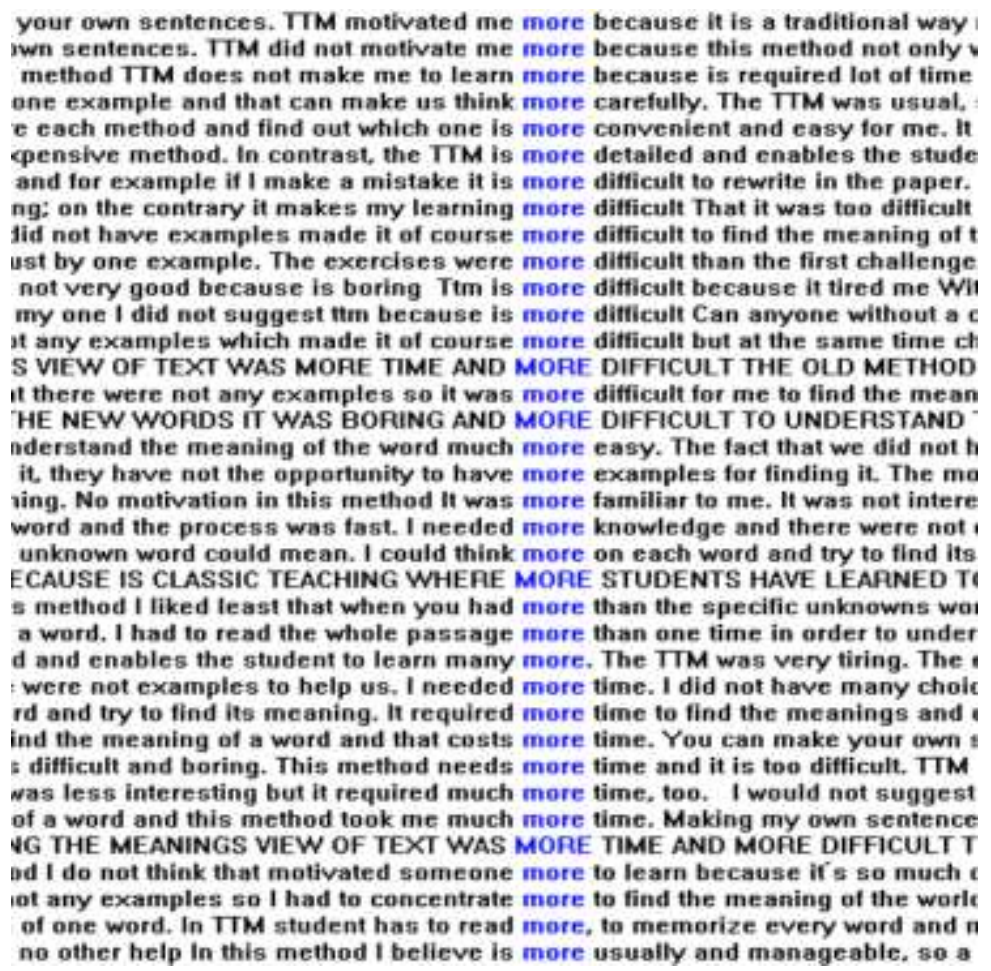

Figure 12. Thirty-six of 36 concordance lines of more from student responses regarding TTM

As shown in Figure 12, the comparative adjective "more" was used 36 times. A brief look at the immediate right collocates of more reveals the students' negative attitude toward TTM because they mostly used the phrases "more difficult," "more time," and so on. However, the corpus-style analysis, drawn from Figure 12, shows how the students used the term "more" at sentence level to explain why they considered TTM "more difficult," "more familiar," and so on. For instance, if we look at the second 
concordance line from the top of Figure 12, “...TTM did not motivate me more because this method not only was less interesting," we can see how the students justified their feelings that they were not motivated by TTM. They seemed to be wondering why TTM might motivate them more and, at the same time, providing the answer in the same sentence. Also, if we look at the first concordance line from the bottom of Figure 12, "I believe is more usual and manageable," we can see how the student explains why they felt TTM has something more to offer. My point is that, apart from calculating the collocates of more to its right or left and drawing conclusions, we can easily look more closely at each concordance line and discern how and why the students used the term "more" in the way they did. This is also particularly useful when triangulating with other types of data involved in this research, namely the OES responses. The corpus-style analysis thus offers a more in-depth picture of what the students were thinking when they used the comparative adjective "more" when commenting on TTM. The evidence offered in Figures 10, 11, and 12 shows that students felt that TTM was more difficult than CTM, which generally means that they believed there was something more involved in the process of learning when using CTM rather than TTM.

\subsubsection{Collocates of meaning}

The next most frequent words after "more" offered by all students when writing about CTM were "word(s)" and "meaning." Between "word(s)" and "meaning," I chose to investigate the collocates of meaning because I thought it would be more interesting to see how my students would evaluate the meaning of unknown vocabulary according to their responses about CTM and TTM. Figure 13 shows the collocates to the immediate left of meaning. I chose to look at the immediate left ones because I mainly wanted to observe what verbs the students put before the noun "meaning" according to their responses about CTM and TTM. The verbs "understand," "find," and "remember" were mostly used by the respondents when commenting on CTM.

14. MonoConc Pro-[Frequency Statistics - [meaning]]
\begin{tabular}{|r|r|r|}
\hline Ih. File Concordance Frequency Display Window Info \\
\hline 18 understand & 54 the \\
14 find & 3 their \\
8 remember & \\
6 the & \\
3 easier & \\
3 out &
\end{tabular}

Figure 13. Left collocates of meaning from student responses regarding CTM 
A first examination of the concordance lines indicated that the students felt that when using CTM, they could understand, find, or remember the meaning of unknown words better than when using TTM. This is shown when looking at the phraseology to the left of the key phrases "understand the meaning" or "found the meaning," and so on. Figure 14 shows these words in context:

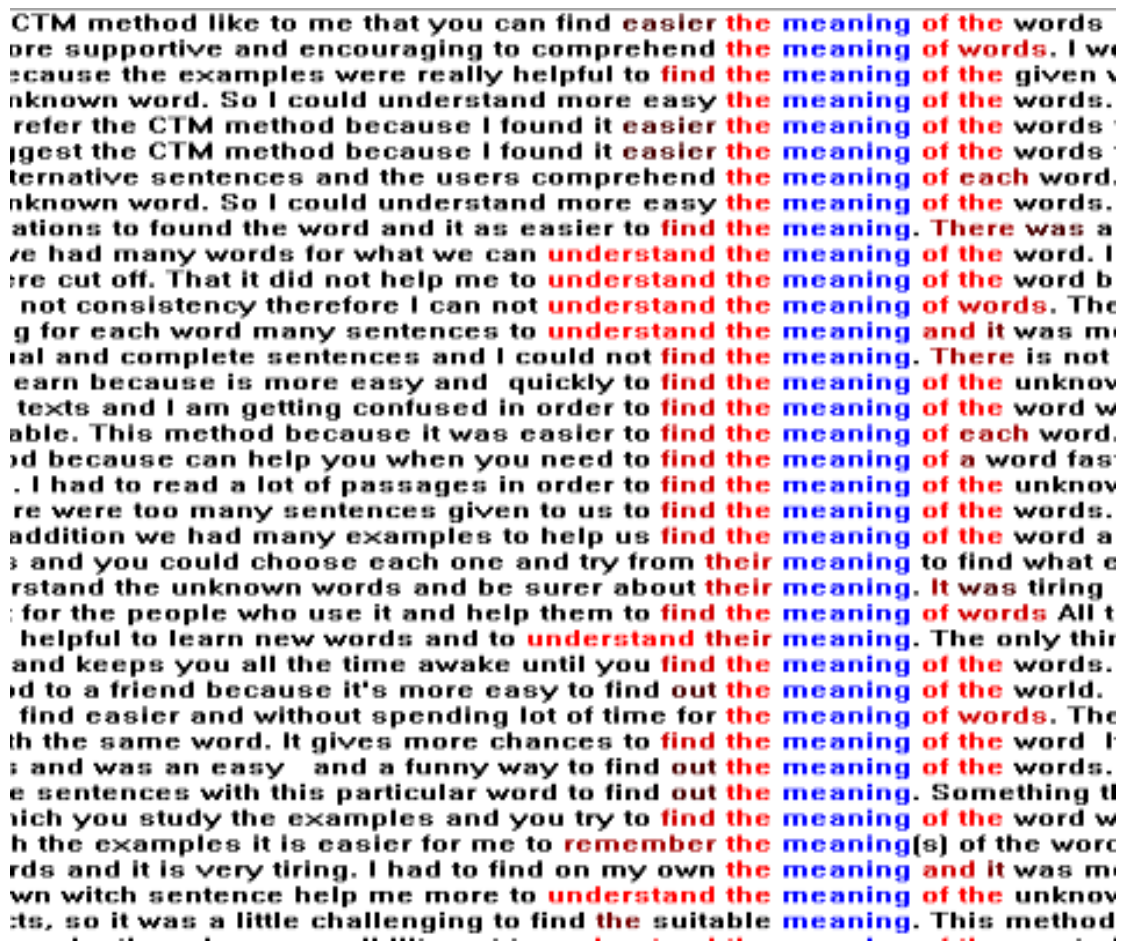

Figure 14. Thirty-six of 69 concordance lines of meaning from student responses regarding CTM

Figure 14 further reveals that the phraseology at sentence level used before the abovementioned key phrases in context is positive such as "help," "be surer," "more easy," "funny way," "many sentences given to us," "gives more chances," and so on. This corpus-style analysis offers a more qualitative observation of the reasons why the students preferred one method over another. For example, if we look at the first concordance line from the top of Figure 14, "...CTM method like to me that you can find easier the meaning of the words," we can see how the student justifies their preference, though their syntax is not accurate.

An analogous search was performed in the corpora of opinions offered by all the students when they wrote about TTM. The KWIC meaning was used again. The immediate left collocates were also examined in more detail, with the results shown in Figure 15: 


14. MonoConc Pro - [Frequency Statistics - [meaning]]
\begin{tabular}{l|l|r|l}
\hline lik File Concordance Frequency Display Window Info & \\
\hline & 2-Left & 37 the \\
\hline 13 find & 4 right \\
11 understand & & -Left \\
8 the
\end{tabular}

Figure 15. Left collocates of meaning from student responses regarding TTM

Figure 15 shows that the verbs "find" and "understand" were most frequently used in student opinions about TTM. It is worthy of note that the verb remember never preceded the noun meaning when the students commented on TTM but it did precede the noun meaning eight times when they commented on CTM (see Figure 13). I would argue that the students associate the retention of target vocabulary with CTM but not with TTM. My findings regarding the association of target vocabulary retention with CTM concurs with the findings of Akbari, Haghverdi, \& Biria (2015) about the retention of collocations and with those of Daskalovska (2015) about better retention of information. Figure 16 shows the phraseology used before the verbs "find" and "understand":

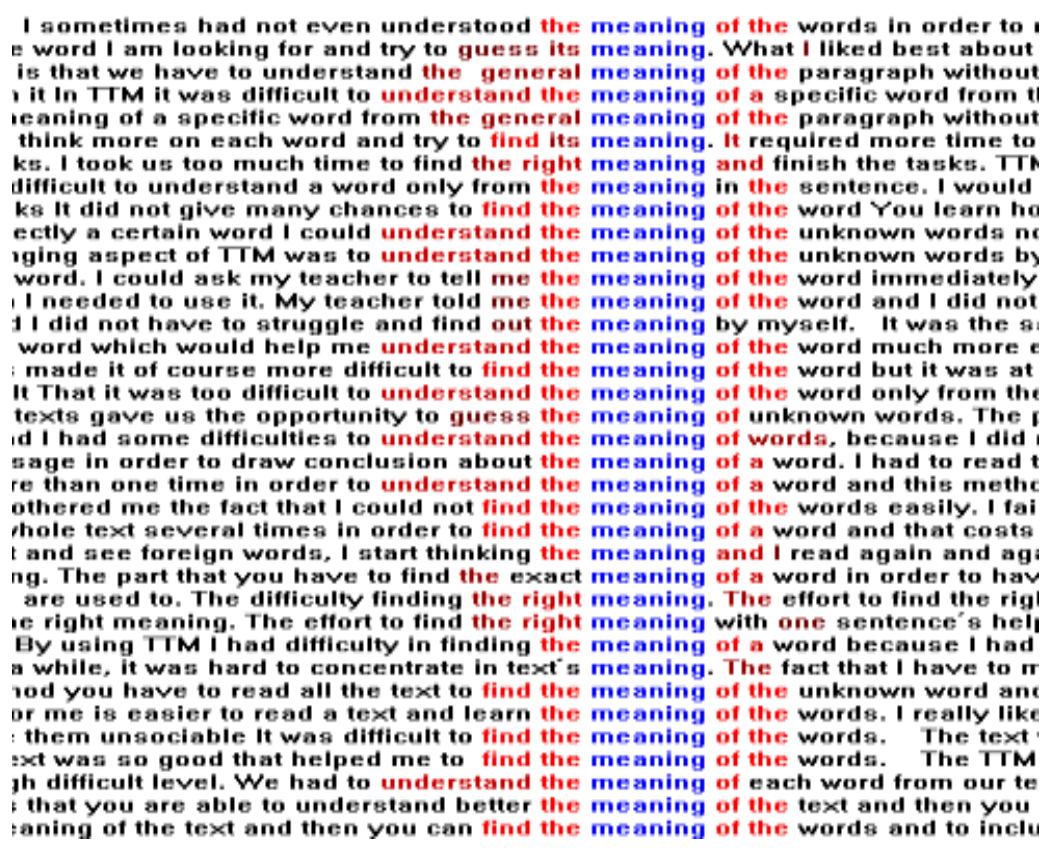

Figure 16. Thirty-six of 52 concordance lines of meaning from student responses regarding TTM

As Figure 16 shows, the phraseology used before the key phrases, "understand the meaning," "find the meaning," "guess the meaning," and so on, is negative, including phrases such as "try," "difficult," "struggle," "my teacher told me," and "hard to concentrate." For example, if we look at the first concordance line from the top of 
Figure 16, the students say "...had not even understood the meaning of the words." Overall, negative phraseology at sentence level before or after the KWIC meaning appears in 18 of 36 concordance lines of Figure 16 (i.e. 1, 3, 4, 6, 7, 8, 9, 16, 17, 19, 22, 23, 26, 28, 29, 30, 32, and 34). A comparison with Figure 14 shows how differently the students negotiated the meaning of unknown words when using one method or the other. It appears that when it comes to CTM, the notion of "meaning" is associated with a more positive context in the students' minds.

\section{DISCUSSION}

The corpus-style analysis of my students' responses presented in this study offered insights into aspects that might help formulate teaching recommendations in the future, including insights from other types of data. By addressing the teaching recommendations, teachers can better meet the ESP learning needs of their students in university settings.

The student responses offered useful reasons about why students liked or disliked CTM and TTM and generally showed how students approached both teaching methods. Also, a corpus-style approach to the analysis of the responses was offered. The students in this study liked CTM more than TTM and this was true at all ability levels, despite reservations that beginners might dislike corpus concordancing because it might be too difficult for them. The aspects of CTM that motivated students to indicate their preference for it were related to convenience and the variety of concordance lines, whereas the aspects that demotivated them were related to boredom and, in a few cases, the appearance of too many concordance lines. The multiplicity of concordance lines and word meanings offered in CTM were identified by intermediate and advanced students as the most challenging aspects of CTM; beginners, however, indicated that their main difficulty was not with the multiplicity of concordance lines, which, on the contrary, was their primary reason for liking CTM, but with computer searches that might take too long to show results and technical issues such as hardware/software compatibility with Windows version, difficulty in adjusting the size/number of characters displayed in each concordance line and limitations in understanding every little detail about the text searching software. Students of different abilities identified various challenges when taught using TTM. Intermediate and advanced students identified contextbased learning as the most challenging aspect; beginners found the shortage of sample sentences a challenge. This seems to indicate that beginners did not actually have a problem with the multiplicity of concordance lines and instead found this aspect helpful and useful. Nearly all the students in this study stated that CTM/DDL motivated their learning more than TTM did. This finding is in line with Mizumoto et al. (2016: 241) who present "the learners' perceived preferences and benefits of DDL," and Marinov (2018: 238) who observes "a more positive attitude towards corpus use" on the part of students. More recently, Forti (2019: 375) found "better 
language gains over time" with the use of DDL, and Elmansi et al. (2021: 59) observed "a positive attitude towards the DDL approach as it is considered to be a useful resource to acquire lexico-grammatical accuracy in order to improve EFL writing." Overall, these aspects lead to positive learner attitudes as regards using corpus concordancing in ESP learning.

I initially thought that not all students in this study would like CTM; however, according to the qualitative findings, all students expressed a preference for CTM due to its convenience and ease. I initially expected that intermediate and beginner students would say that they liked the variety of concordance lines less often than the advanced students; however, they indicated that they liked the variety of concordance lines more often than the advanced students. A potential explanation for these findings is that intermediate and beginner level students may have already been disappointed by TTM before being exposed to CTM, so they had a positive attitude toward the latter method, whereas advanced students might have felt more confident with either teaching method and were thus more reserved.

\section{CONCLUSION}

The aspects of CTM that motivated the students' learning more were linked to creativity and interest, with the variety of concordancing lines establishing more motivation among beginners and intermediate students rather than advanced ones. I conclude that all students regarded CTM as being creative and interesting and this finding should encourage teachers to include CTM in their teaching syllabus. Finally, nearly all the students in this study at all ability levels indicated that they would recommend CTM to a friend for several reasons but only a few held the same opinion about TTM and would not even say why. The aspects that motivated them to prefer CTM were linked to effectiveness and interest. I argue that CTM seems to have established itself as a better approach in the minds of the students, which should be considered by a teacher when modifying their teaching syllabus decisions. The above corpus-style analysis shows that CTM motivates ESP university students more effectively than the existing traditional learning method; hence a university teacher may wish to exploit the higher potential of CTM to interest students and to enhance motivation in their classroom.

The present study has a few limitations that should be acknowledged. Depending on the research focus and availability of space, a greater number of comparative adjectives could have been incorporated in the collocation analysis, for example, words ending in "-er" to supplement the analysis of "more", or the "-n't" contraction to supplement the study of "not." It should also be acknowledged that frequency is not necessarily the most important criterion, as sometimes interesting observations are made and conclusions are drawn from single words or phrases.

This study showed that CTM can open new teaching and learning horizons in ESP university contexts in Greece and other countries. The utilization of corpus 
concordancing tools to cover ESP students' learning needs can make learning different, effective, and more interesting. CTM may also provide an opportunity for ESP teachers and students at university level to create their own small and flexible corpora to suit the needs of their particular area of study.

[Paper submitted 4 May 2021]

[Revised version received 25 Aug 2021]

[Revised version accepted for publication 1 Nov 2021]

\section{References}

Akbari, J., Haghverdi, H., \& Biria, R. (2015). Instructional efficacy of corpus-based tools in teaching collocations to Iranian university students with different majors. Journal of Applied Linguistics and Language Research, 2(8), 218-229.

Allan, R. (2009). Can a graded reader corpus provide 'authentic' input? ELT Journal, 63(1), 23-32. https://doi.org/10.1093/elt/ccn011

Barlow, M. (2003). Concordancing and corpus analysis using MP2.2. Athelstan.

Busse, V., \& Walter, C. (2013). Foreign language learning motivation in higher education: A longitudinal study of motivational changes and their causes. The Modern Language Journal, 97(2), 435-456. https://doi.org/10.1111/j.1540-4781.2013.12004.x

Chang, J. Y. (2014). The use of general and specialized corpora as reference sources for academic English writing: A case study. ReCALL, 26(2), 243-259. https://doi.org/10.1017/S0958344014000056

Cook, T. D., \& Campbell, D. T. (1979). Quasi-experimentation: Design \& analysis issues for field settings. Houghton Mifflin Company.

Craig, D. V. (2009). Action research essentials. John Wiley \& Sons, Inc.

Creswell, J. W. (2009). Research design: Qualitative, quantitative, and mixed methods approaches (3rd ed.). Sage Publications.

Daskalovska, N. (2015). Corpus-based versus traditional learning of collocations. Computer Assisted Language Learning, 28(2), 130-144. https://doi.org/10.1080/09588221.2013.803982

De Vaus, D. (2001). Research design in social research. Sage Publications, Inc.

Dörnyei, Z. (2007). Research methods in applied linguistics: Quantitative, qualitative, and mixed methodologies. Oxford University Press.

Elmansi, H. M., Dadour, D., Mohamad, E. S., Qoura, D., AbdelSamea, A., Hamada, D., \& Ali, T. (2021). The impact of data-driven learning based program on developing student teachers' lexico-grammatical performance skills in EFL writing. Journal of Research in Curriculum Instruction and Educational Technology, 7(3), 37-65. https://dx.doi.org/10.21608/jrciet.2021.181573

Forti, L. (2019). Evaluating data-driven learning effects in the Italian L2 classroom: Etic and emic perspectives combined. EL.LE, 8(2), 363-378. http://doi.org/10.30687/ELLE/22806792/2019/02/006

Gay, L. R., Mills, G. E., \& Airasian, P. (2009). Educational research: Competencies for analysis and applications (9th ed.). Pearson Education, Inc.

Geluso, J., \& Yamaguchi, A. (2014). Discovering formulaic language through data-driven learning: Student attitudes and efficacy. ReCALL, 26(2), 225-242. https://doi.org/10.1017/S0958344014000044 
Gries, S. T. (2013). 50-something years of work on collocations: What is or should be next... International Journal of Corpus Linguistics, 18(1), 137-166. https://doi.org/10.1075/ijcl.18.1.09gri

Hasko, V. (2013). Qualitative corpus analysis. In C. A. Chapelle (Ed.), The encyclopedia of applied linguistics (pp. 4758-4764). Blackwell.

Kennedy, G. (2014). An introduction to corpus linguistics. Routledge.

Keren, G., \& Lewis, C. (2014). A handbook for data analysis in the behavioral sciences: Volume 1: Methodological issues: Volume 2: Statistical issues. Psychology Press.

Mahlberg, M. (2005). English general nouns: A corpus theoretical approach. John Benjamins Publishing Company.

Mair, C. (1996). Machine readable text corpora and the linguistic description of languages. In C. Züll, J. Harkness, \& J. H. P. Hoffmeyer-Zlotnik (Eds.), Text analysis and computers (pp. 64-75). Zentrum für Umfragen, Methoden und Analysen (ZUMA). Retrieved from https://nbn-resolving.org/urn:nbn:de:0168-ssoar-49737-2

Marinov, S. (2018). Corpatt: A scale for measuring attitudes towards corpus use. Strani jezici: časopis za primijenjenu lingvistiku, 47(4), 221-242.

Meltzoff, J. (2010). Critical thinking about research: Psychology and related fields (11th ed.). American Psychological Association.

Mizumoto, A., Chujo, K., \& Yokota, K. (2016). Development of a scale to measure learners' perceived preferences and benefits of data-driven learning. ReCALL, 28(2), 227-246. https://doi.org/10.1017/S0958344015000208

O’Keefe, A., McCarthy, M., \& Carter, R. (2007). From corpus to classroom: Language use and language teaching. Cambridge University Press.

Önder-Özdemir, N. (2014). Using corpus data to teach collocations in medical English. Journal of Second Language Teaching \& Research, 3(1), 37-52.

Plano Clark, V. L., \& Creswell, J. W. (2010). Understanding research: A consumer's guide. Pearson Education, Inc.

Sinclair, J. (1990). Corpus, concordance, collocation. Oxford University Press.

Sinclair, J. (2003). Reading concordances: An introduction. Longman.

Tong, A., Sainsbury, P., \& Craig, J. (2007). Consolidated criteria for reporting qualitative research (COREQ): A 32-item checklist for interviews and focus groups. International Journal for Quality in Health Care, 19(6), 349-357. https://doi.org/10.1093/intqhc/mzm042

Tribble, C. (1997, April). Improvising corpora for ELT: Quick and dirty ways of developing corpora for language teaching. Paper presented at the First International Conference: Practical Applications in Language Corpora, Łódź, Poland. Retrieved from https://www.ctribble.co.uk/text/Tribble_C_Palc_97.pdf

VASSILIS ARGYROULIS has been teaching ESP for twenty years at the University of Thessaly, Greece. He has been researching corpus concordancing and the way it can be used in ESP teaching and learning at university/tertiary level. He obtained his $\mathrm{PhD}$ in Applied Linguistics from the University of Nottingham, UK. 


\section{Appendix 1}

\section{Worksheet 1 for use with CTM and SP1 (Specialized Passage 1)}

Linguistic Tasks Stage:

TASK 1: Reading Comprehension of SP1.

Read SP1 in the handout. Then look at the 10 words given and, with the use of the electronic corpus concordancer, try to understand the meaning of the ten given words and finally write their possible meaning in English or in Greek (the ten words are in bold and underlined in the text).

TASK 2: Fill in the gapped sentences using the words below in any suitable form and the corpus concordancer provided: pervasive, underpin (verb), detriment, caveat, provision, lobby (verb), inclusive, disproportionate, favour (verb), mainstream (adjective)

TASK 3: Make your own sentences using the ten words given below and concordance lines you will find in MP2.2. Do not copy the concordance lines:

TASK 4: Underline (or put an $X$ in the square next to) the meaning(s) of caveat. Wrong meanings count against your score. The 29 concordance lines below can help you:

1.... samples drawn from different locales, but this caveat applies to almost all published ASD scales, ...

2.... he's expected to obtain a mark of 65 . The same caveat applies here. Equation E3e shows that ...

3 .... that his mark would be $51.3 \%$. Again, the same $\underline{\text { caveat }}$ applies. To test whether exam performance is ...

4.... and adults. There is no age barrier. The only caveat is that if the language training starts after puberty...

5 .... is the logical next step for this project. Another caveat is that, in the AS subjects of our study, a reduced ...

6.... (see summary in Newcomb et al., 1993). A further caveat is that the present study used only one method ...

7.... commonly used statistic and we present it with the caveat that it must be interpreted more cautiously than ...

8.... and what we know now, but always with a kind of caveat that we've now learned that again these are not ...

9. ... there should be a warning or something, or a caveat, that says in some cases using manipulatives on ...

10 ....entered the current investigation with the known caveat that clusters are simply another form of categorical system ...

11....made above. However, we would want to add the caveat that the weighting attached to any outcome arrived ...

$12 . .$. We give below an example, but must enter the caveat that because of its small order $(n=3)$ it converges ...

13.... administration of the test was followed with the caveat that instructions were delivered in ASL rather than ...

14.... question about informational text and kind of a caveat. That is, as much as possible you would like these ...

15.... offers this document on the Internet with the caveat that, while readers can gain basic information about ...

16.... you have a richer report for that, all with the caveat that one example isn't the only way to achieve a ...

17.... For example, there is no need to include a caveat that a frog is in pain if its input is I, and its output $0, \ldots$

18. ... thought that that would be useful and with the caveat that the sample of the standards may differ over time....

19. ... questions on the test. And then, there was this caveat that said the further you get up the hierarchy, ...

20 .... which would be used for teachers and with a caveat that it isn't valid from year to year. An item analysis ...

21 .... one of them is, a- again just to stress this caveat that a lot of this, sort of logic, was built up in ...

22.... thing in more than one manner. We offer one caveat to these specific conclusions. Research on persons ...

23. ... Attention must, however, be drawn to a crucial caveat to these rules. Case-law demonstrates that ...

24 .... uncertainty as to the validity of such decisions". The caveat to perpetual uncertainty is that where a decision ...

25 .... need not be the maximum profit. The final caveat to the question is that even if firms recognize that ...

26 .... kinds of passages. And she just sort of gave us a caveat to sort of think about that as you do that....

27. ... rather than differences in attention. An important caveat to this is that further studies are required to test ...

28. ... from regular walking. It is important to add a caveat to these findings, which are, in essence, ...

29.... include many psychological studies. An additional caveat to this is that any benefits should be gained ...

Meaning 1: An announcement containing information about an event

Meaning 2: A warning against certain acts

Meaning 3: A statement that limits or restricts some claim

Meaning 4: A type of expensive food served in luxury restaurants

Meaning 5: Anything we use to cover or hide something

Meaning 6: A positive result of a hard effort

Meaning 7: A kind of an answer or response to someone

Meaning 8: (law) A formal notice placed with a court or officer to stop a

legal proceeding until the person who places the notice is given a hearing.

Meaning 9: A pleasant comment or remark

Meaning 10: A pleasurable activity performed

Questionnaire Stage

Students fill in the CTM motivational questionnaire (Parts I, II, and III) given by the teacher. 


\section{Appendix 2}

\section{Motivational questionnaire about CTM (Parts I, II, and III)}

General instruction:

I would like to ask you to help me by answering the following questions concerning foreign language learning. The following questions are given to you by me to better understand your thoughts and beliefs as learners of English. Please, read carefully the instructions and write your answers in each one of the sections. This is not a test so there are no "right" or "wrong" answers and you do not even have to write your name on it. The results of this survey will be used only for research purposes so please give your answers sincerely. The contents are totally confidential. Thank you very much for your help!

Part I: In this part, I would like to ask you to tell me how much you agree or disagree with the following statements by simply circling a number from 1 to 6 . Please do not leave out any of items.

\begin{tabular}{|l|l|l|l|l|l}
\hline Strongly disagree & Disagree & Slightly disagree & Slightly agree & Agree & Strongly agree \\
\hline 1 & 2 & 3 & 4 & 5 & 6 \\
\hline \multicolumn{4}{|l|}{ Example: If you strongly agree with the following statement, write this: } \\
\hline
\end{tabular}

\begin{tabular}{|c|c|}
\hline 1. The place of the lesson was convenient. & 123456 \\
\hline 2. The tasks required critical thinking which made my learning easier. & 123456 \\
\hline 3. The way the lesson was taught was a good aid to learning. & 123456 \\
\hline 4. I need more help to totally understand words dealt with in the lesson. & 123456 \\
\hline 5. The tasks were helpful for learning meaning of unknown vocabulary. & 123456 \\
\hline 6. I was very confident in my abilities to use the passage. & 123456 \\
\hline 7. I enjoyed filling in the sentences in Task 2 . & 123456 \\
\hline 8. I am very satisfied with the lesson. & 123456 \\
\hline 9. The tasks required application of problem-solving skills which made my learning easier. & 123456 \\
\hline 10. The method of presentation was easy to follow. & 123456 \\
\hline 11. I think I will remember the words any time I meet them in the future. & 123456 \\
\hline 12. I would like to participate in another similar lesson. & 123456 \\
\hline 13. The activity was helpful for learning the usage of vocabulary. & 123456 \\
\hline 14. I think I received new words in this lesson. & 123456 \\
\hline 15. The classroom was comfortable enough for the activities. & 123456 \\
\hline 16. This class experience has helped me improve my reading skills. & 123456 \\
\hline 17. I found working with the passage very easy. & 123456 \\
\hline 18. This class experience has helped me improve my learning skills. & 123456 \\
\hline 19. The learning materials were convenient. & 123456 \\
\hline 20. The lesson made me much more productive. & 123456 \\
\hline 21. The teacher was an active class member offering direction where needed. & 123456 \\
\hline 22. I was able to get personal attention from my teacher when needed. & 123456 \\
\hline 23. I feel confident to produce relevant sentences on my own in the future. & 123456 \\
\hline 24. The lesson did not meet my learning needs. & 123456 \\
\hline 25. The teacher is knowledgeable enough for the type of activities I did. & 123456 \\
\hline 26. I would recommend the lesson to others. & 123456 \\
\hline 27. The time of the lesson was convenient. & 123456 \\
\hline 28. I do not feel confident enough to handle similar tasks in the future. & 123456 \\
\hline $\begin{array}{l}\text { 29. In the future, I will be able to deal with a new but relevant activity and understand unknown words following } \\
\text { this learning approach. }\end{array}$ & 123456 \\
\hline 30. The lesson made learning more interesting. & 123456 \\
\hline 31. I enjoyed working with the passage. & 123456 \\
\hline 32. I felt the need to ask for synonyms of some unknown words. & 123456 \\
\hline 33. I enjoyed making sentences in Task 3 . & 123456 \\
\hline 34. It was hard for me to deal with Task 4 . & 123456 \\
\hline 35. In Task 4, I could discover different meanings of the given & 123456 \\
\hline
\end{tabular}


Part II (on Thessaly Corpus):

\begin{tabular}{|l|l|l|}
\hline 1. The operation of the Thessaly Corpus was stable. & 123456 \\
\hline 2. The Thessaly Corpus provided content that exactly fitted my needs. & 123456 \\
\hline 3. I feel good about the idea of a new syllabus which will include the Thessaly Corpus. & 123456 \\
\hline 4. In this Thessaly Corpus lesson I feel I learnt more than I used to. & 123456 \\
\hline 5. The Thessaly Corpus should be used in learning vocabulary. & 123456 \\
\hline 6. The Thessaly Corpus should be used in learning syntax. & 123456 \\
\hline 7. The Thessaly Corpus provided interesting content. & 123456 \\
\hline 8. I feel the Thessaly Corpus lessons are more effective than the lessons I used to have. & 123456 \\
\hline 9. The Thessaly Corpus provided up-to-date content. & 123456 \\
\hline 10. The Thessaly Corpus was easy to use. & 123456 \\
\hline 11. The Thessaly Corpus made it easy for me to find the content I needed. & 123456 \\
\hline 12. The Thessaly Corpus was user-friendly. & 123456 \\
\hline 13. The Thessaly Corpus provided sufficient content. & 123456 \\
\hline 14. The Thessaly Corpus was easy to access. & 123456 \\
\hline 15. I had some difficulty in using the Thessaly Corpus due to unfamiliar vocabulary on concordance lines. & 123456 \\
\hline 16. The Thessaly Corpus provided personalized learning support. & 123456 \\
\hline 17. I had some difficulty in using the Thessaly Corpus due to cut-off sentences in concordance output. & 123456 \\
\hline 18. The Thessaly Corpus responded to my requests fast enough. & 123456 \\
\hline 19. The teaching methods provided by the Thessaly Corpus were easy to understand. & 123456 \\
\hline 20. I had difficulty in using the Thessaly Corpus due to too many sentences in concordance output. & 1236 \\
\hline
\end{tabular}

Part III

Please provide the following information by ticking $(\sqrt{ })$ in the box or writing your response in the space provided.

Full name: Gender: $\quad$ Male $\square$ Female

Nationality: $\square$ Greek $\square$ Non-Greek Age: $\square 18 \square 19 \square 20 \square 21 \square 22$ Other:...

Year of English studies: $\square 1 \square 2 \square 3 \square 4 \square 5 \square 6 \square 7$ व8 Other:

Your level according to placement test: $\square$ Beginner Intermediate $\square$ Advanced

Thank you for your cooperation 